\title{
Barriers to End-of-life Discussions in the Primary Care Setting
}

\author{
Devon S. Boydstun, DO'; Shandra Basil, OMS-IV2; Jill Porter, DO3; Anand Gupta, MBBS, MPH
}

'OhioHealth Doctors Hospital Family Practice, Columbus, $\mathrm{OH}$

2Ohio University Heritage College of Medicine, Athens, $\mathrm{OH}$

${ }^{3}$ OhioHealth Doctors Hospital Family Practice, Columbus, $\mathrm{OH}$

${ }^{4}$ OhioHealth Research and Innovation Institute, Columbus, $\mathrm{OH}$

KEYWORDS:
Advanced Care Planning
End-Of-Life
Palliative
Primary Care

\section{INTRODUCTION}

The Patient Self-Determination Act (PSDA) was passed in 1991 and requires hospitals, skilled nursing facilities, home healthcare agencies, and providers of home healthcare to: (1) provide patients with a written summary of patients' healthcare decisionmaking rights and the facilities' policies with respect to advance directives; (2) ask individuals at the time of admission if they have an advance directive; and (3) provide education to staff and the community about advance directives. ${ }^{1}$ Despite increased advocacy and awareness for advance care planning (ACP), more recent studies were no more successful than studies completed

\section{CORRESPONDENCE:}

Devon S. Boydstun, DO | devon.boydstun@ohiohealth.com

Copyright $\odot 2020$ by the American College of Osteopathic Family Physicians. All rights reserved. Print ISSN: 1877-573X

DOI: $10.33181 / 12021$ shortly after passage of the PSDA, with success defined as patient completion of ACP documents. ${ }^{2}$ Although it is required through the PSDA to "educate patients," there is no requirement in regards to monitoring completion rates, which is likely a contributing factor to low completion rates of advance directives in the US. Could this also be due to the fact that patients opt to not complete them, or due to lack of discussion and understanding?

Multiple studies have shown the existence of certain barriers to having these discussions. From the perspective of physicians, barriers to having these discussions include: lack of time; low health literacy of patients; lack of necessary skills; lack of privacy for discussions; and patients not being "sick enough." ${ }^{2}$ From the patient perspective, barriers to completing ACP documents include: deferring to family members or physicians; inconsistency with religious beliefs; too distressing to think about; difficulty completing documents; and planning to do it later. ${ }^{2}$ These reasons, in addition to lack of comfort, concern for depression in patients, and lack of confidence in prognosticating abilities, are based mostly on observational studies and pertain to a very specific area 
of medicine (such as chronic kidney disease) instead of medicine and aging in general. ${ }^{3,4,5}$ To our knowledge, there has yet to be a detailed study on the perceptions of physicians as to the barriers to holding end-of-life or advanced care planning discussion with their patients. These discussions are imperative to carrying out patient wishes while also being cognizant of the physician commitment to "do no harm" as it relates to futile, invasive treatments. This is supported by the fact that, paradoxically, patients diagnosed with a severe, life-limiting illness who are introduced to palliative care early in their disease course live an average of $25 \%$ longer than those who pursue aggressive treatments. ${ }^{6}$

Despite these good outcomes being adequately researched and presented, a majority of end-of-life discussions occurred in the acute setting during a hospitalization. ${ }^{7}$ In addition, upon diagnosis with a serious, life-limiting illness such as end-stage renal disease (ESRD) requiring dialysis, $90 \%$ of patient's reported that they had not discussed prognosis with their physician. ${ }^{8}$ This is staggering as there is an annual mortality rate in these patients of $22 \% .^{8}$ If this were not evidence enough of the void that has been created surrounding end-of-life discussion, $61 \%$ of ESRD patients requiring dialysis wish in hindsight that they would have never started it, the alternative to which would have been death. ${ }^{9}$

Prior studies have shown that patients want their primary care doctor to initiate advance care planning while they are in good health. ${ }^{10}$ Moreover, one investigation revealed that patients felt that advanced directive discussions should occur earlier than physicians did across several important domains (i.e., at an earlier age, earlier in the natural history of disease, and earlier in the patient-physician relationship). ${ }^{11}$ In addition, most patients felt that it was the physician's responsibility to initiate the discussion about advance care planning. ${ }^{11}$ It seems most appropriate that these discussions would occur in the primary care setting between the patient and their physician with whom they have built a good relationship, who knows their medical history, and who plans to see them and care for them in the future. Advanced care planning regarding serious illness is ideally carried out well before such a diagnosis is made. Many studies indicate that by having endof-life or goals of care discussions, patient's desires are carried out more frequently, healthcare resources are preserved, and patient's surrogate stress decreased. . $2,13,14^{2}$

The benefits of early advanced care planning and/or end-of-life discussions are plainly clear, however, it is also clear that these discussions are not taking place as often as they should. This study aims to determine exactly why primary care physicians are, by and large, not having these discussions with their patients. In addition, it will characterize by level of experience, gender, age, and practice setting the comfort level of primary care physicians regarding this topic.

\section{Specific Aims}

The goal of this study is to describe feedback from primary care physicians (PCPs) regarding end-of-life discussions with patients. This project is designed as an anonymous survey to be administered to physicians from three large healthcare systems in a large Midwestern city, with the following specific aims:
Aim 1. Describe physician-reported comfort level with initiating and engaging in end-of-life discussions with patients. Describe physician-reported barriers to end-of-life discussions.

Aim 2. Describe proportion of patients with whom physician reports having end-of-life discussions, and evaluate if this varies based on physician/practice characteristics, or patient demographics.

\section{METHODS}

\section{Study Population}

The study population included family medicine residents and attending physicians from 3 large healthcare centers from a large Midwestern city.

\section{Study Variables \& Outcomes of Interest}

The following data was collected via anonymous survey, by means of project-specific REDCap data collection database and paper surveys. Only the study staff had access to the responses collected in this study. No identifiers were collected.

\section{Study Design}

\section{Overall Design}

This study was a prospective, anonymous survey to evaluate how end-of-life discussions take place among primary care providers and what barriers exist to holding such discussions. Responses were collected responses from PCPs from central Ohio, including both resident and attending physicians who attended the bi-annual Family Medicine Affiliation Conference, in a large Midwestern city. This affiliation conference occurs twice a year as an educational and networking event.

Eligible physicians received a cover letter and survey regarding end-of-life discussions. Participants were asked to submit responses to participate in this study. Participation was voluntary.

Participants were not excluded on gender, sexual orientation, socioeconomic, racial, or religious identity.

\section{Data Storage and Confidentiality}

Only de-identified or non-identifiable data was reported in the study. In addition to collection and storage of data in the HIPAAcompliant, web-based REDCap database and in paper files, resulting data will be stored in electronic format; electronic files will be stored on a password-protected computer and paper files will be stored in a locked office. The data collection and storage processes will follow HIPAA guidelines in accordance with 21 CFR 46.115 (b): to protect both confidentiality and privacy of each participant.

\section{Risks \& Benefits, Bias}

The only potential risk associated with this study was loss of confidentiality, which was be minimized by collecting anonymous surveys, as well as limiting access to data. Participants did not expect any direct benefit from participating in the study; however, 
the outcomes of the study might have identified deficits in continuing medical education (CME), which may prompt CME opportunities. The information from this study will be used to describe PCP feedback on end-of-life discussions with patients, including frequency and barriers.

\section{Statistical Analysis}

Demographics and physician/ practice characteristics were described using means, medians and standard deviations for continuous variables and compared using two-sample tests or Wilcoxon Mann Whitney U tests. Discrete variables were described using frequencies and percentages and compared using Chisquare tests or Fisher's exact test between the groups made by the answer to "As a PCP, do you have end-of-life discussions with your patients?" and overall.

\section{Results}

The results of this study are in Table 1 . There were $n=74$ PCPs involved in this study. The groups being compared are those that answered yes vs. no on the question, "As a PCP, do you have endof-life discussions with your patients?" One PCP did not answer this question, so there was a total of $n=73$ PCPs for this study, with $n=8$ for No and $n=65$ for Yes.

Those in the "Yes" Group were statistically significantly older than those in the "No" Group, median (range) of 31(26 to 53) vs. 28(26 to 34 ), respectively, $p=0.0364$.

Those in the "Yes" Group were statistically significantly more comfortable initiating and engaging in these conversations compared to those in the "No" Group, $44.6 \%$ (29/65) vs. 25\% (2/8), $p<0.0001$.

$100 \%$ of those in the No Group were still in their residency training.

The most common barrier indicated for not holding end of life discussions in both the "Yes" Group and the "No" Group was lack of time during office visits ( $50 \%$ and $69 \%$, respectively).

\section{DISCUSSION}

This study clearly showed that age and time in practice were major factors in holding end of life discussions with patients. This may be attributed to experience, a better knowledge of communication methods, longer relationships with patients, or any combination therein. The most common reason indicated for not holding such discussions, lack of time during office visits, is a trend that is seen nationwide among primary care physicians. The shorter and shorter office visits create an environment that is less conducive to holding serious conversations. Potential ways to overcome these issues include billing based on time and/or having specific visits to address goals of care which is now a billable ICD-10 code.

This study was limited in sample size to those present during the aforementioned conference. Additionally, the sample was representative only to PCPs in one Midwestern city. There may also have been some response and social desirability bias among the answers provided. Lastly, while there was a decent range in years of practice, a large majority of those surveyed were

\section{TABLE 1:}

Reactions to methamphetamine ${ }^{12}$

\begin{tabular}{|c|c|}
\hline CATEGORY & DATA POINTS \\
\hline $\begin{array}{l}\text { Participant } \\
\text { Demographics }\end{array}$ & $\begin{array}{l}\text { 1. Age (y) } \\
\text { 2. Gender (male, female) } \\
\text { 3. Medical degree (MD, DO) } \\
\text { 4. Practice setting (urban, sub-urban, rural) } \\
\text { 5. Duration of PCP career (resident; less than } \\
5 \text { years, } 5 \text { to } 10 \text { years, } 11 \text { to } 20 \text { years, greater } \\
\text { than } 20 \text { years) } \\
\text { 6. Have you ever participated in formal training } \\
\text { on how to have end-of-life/advanced directives } \\
\text { discussions with patients? (yes/no) }\end{array}$ \\
\hline $\begin{array}{l}\text { Advanced } \\
\text { Directives } \\
\text { Feedback }\end{array}$ & $\begin{array}{l}\text { 1. As a PCP, do you have end-of-life discussions } \\
\text { with your patients? } \\
\text { a. No, I do not have end-of-life discussions } \\
\text { with my patients. } \\
\text { b. Yes, I have end-of-life discussions with } \\
\text { some of my patients. } \\
\text { c. Yes, I have end-of-life discussions with } \\
\text { most of my patients. } \\
\text { d. Yes, I have end-of-life discussions with } \\
\text { all of my patients. }\end{array}$ \\
\hline
\end{tabular}

2. If you have end-of-life discussions with your patients, please describe your level of comfort initiating and engaging in these conversations:
a. Not at all comfortable
b. Hesitant
c. Comfortable
d. Very Comfortable
e. Not Applicable - I do not have these conversations with my patients.

3. What is the primary barrier that prevents you from initiating or engaging in end-of-life discussions with patients?
a. Not enough time during appointments
b. Level of comfort
c. Knowledge of relevant issues surrounding end-of-life decisions (e.g. advanced directives/living wills, health care power of attorney)
d. Concern that it will increase patient anxiety
e. Not the responsibility of the PCP
f. Other (describe):

4. At what age should patients have advanced directives established?
a. All adult patients should discuss and record end-of-life preferences
b. Age 35-50
c. Age 51-65
d. Age 66+ 


\begin{tabular}{|l|l|}
\hline $\begin{array}{l}\text { Advanced } \\
\text { Directives }\end{array}$ & $\begin{array}{r}\text { 5. What health status prompts you to have } \\
\text { end-of-life planning discussions with your } \\
\text { patients? } \\
\text { a. have end-of-life discussions with most } \\
\text { or all of my patients, no matter their } \\
\text { health status. } \\
\text { b. I have end-of-life discussions with my } \\
\text { patients who have chronic but } \\
\text { manageable disease/health concerns. } \\
\text { c. I have end-of-life discussions with my } \\
\text { patients who have non-manageable or } \\
\text { untreated disease/health concerns. } \\
\text { d. I have end-of-life discussions with my } \\
\text { patients who have terminal disease. } \\
\text { e. Not applicable - I do not have these } \\
\text { conversations with my patients. } \\
\text { 6. At what age do you most often initiate } \\
\text { end-of-life discussions? } \\
\text { a. Any adult patient } \\
\text { b. Age } 35-64 \\
\text { c. Age 65+ } \\
\text { d. Not applicable-I do not have these } \\
\text { conversations with my patients. } \\
\text { 7. What percentage of patients have you had } \\
\text { end-of-life discussions? } \\
\text { a. Less than } 25 \% \\
\text { b. } 26-50 \% \\
\text { c. } 51-75 \% \\
\text { d. } 76-100 \%\end{array}$ \\
\end{tabular}

resident physicians or very early in their career. Strengths of this study included surveying physicians across a broad spectrum of experience, ability to indicate personal barriers to end of life discussions, and assessing if there was a difference between practice settings.

Additional research is needed in this area to better identify broader trends in barriers to holding end of life discussions as well as to determine what standardized methods may be employed in encourage holding these discussions more often.

\section{CONCLUSION}

While a majority of primary care physicians report holding end of life discussions with their patients, a review of the literature suggests most patients end up having these discussions in the acute setting while hospitalized. Our evidence supports the hypothesis that older physicians who are further along in their career have a higher degree of comfort having end of life discussions with their patients. This is possibly due to their relative advanced experience level but also may be a measure of how long they have known their patients. While multiple barriers exist to having these discussions, it appears that lack of time during office visits is the most common problem indicated. Further studies are necessary to decipher why most end of life discussions are happening after an acute event rather than in a controlled office setting by the primary care physician. Through this additional research, primary care physicians could better identify broader trends in barriers to holding end of life discussions as well as to determine what standardized methods may be employed in encourage holding these discussions more often.

\section{Acknowledgements}

The authors gratefully acknowledge the support of the OhioHealth Research \& Innovation Institute, in particular Chelsey Blessing for their contribution to study protocol, design, and analysis.

\section{AUTHOR DISCLOSURES:}

No relevant financial affiliations or conflicts of interest.

\section{REFERENCES:}

1. American Bar Association. Health Care Advance Directives: What Is the Patient Self-Determination Act [on-line]. Available at www.abanet.org/ publiced/practical/patient_self_determination_act.html Accessed July 13, 2005.

2. Ramsaroop SD, Reid MC, Adelman RD. Completing an advance directive in the primary care setting: what do we need for success? J Am Geriatr Soc. 2007;55(2):277-283.

3. Rachelle E. Bernacki, MD, MS; Susan D. Block, MD. Communication About Serious Illness Care Goals: A Review and Synthesis of Best Practices. JAMA Intern Med. 2014;174(12):1994-2003. doi:10.1001/ jamainternmed.2014.5271 Published online October 20, 2014.

4. Janssen DJ, Spruit MA, Schols JM, etal. Predicting changes in preferences for life-sustaining treatment among patients with advanced chronic organ failure. Chest. 2012;141(5):1251-1259.

5. Davison SN. End-of-life care preferences and needs: perceptions of patients with chronic kidney disease. Clin J Am Soc Nephrol.2010;5(2):195-204.

6. Temel JS, Greer JA, Muzikansky A, etal. Early palliative care for patients with metastatic non-small-cell lung cancer. N EngI J Med. 2010;363 (8):733-742.

7. Mack JW, Cronin A, Taback N, etal. End-of-life care discussions among patients with advanced cancer: a cohort study. Ann Intern Med. 2012;156(3): 204-210.

8. Davison SN. End-of-life care preferences and needs: perceptions of patients with chronic kidney disease. Clin J Am Soc Nephrol. 2010;5(2):195-204.

9. Davison SN. End-of-Life Care Preferences and Needs: Perceptions of Patients with Chronic Kidney Disease. Clin J Am Soc Nephrol. 2010 Feb; 5(2): 195-204. Doi 10.2215/CJN.05960809.

10. Maxfield CL, Pohl JM, Colling K. Advance directives: A guide for patient discussions. Nurse Pract 2003;28:38-47.

11. Johnston SC, Pfeifer MP, McNutt R. The discussion about advance directives: Patient and physician opinions regarding when and how it should be conducted. Arch Intern Med 1995;155:1025-1030.

12. Zhang B, Wright AA, Huskamp HA, et al. Health care costs in the last week of life: associations with end-of-life conversations. Arch Intern Med. 2009; 169(5):480-488.

13. Detering KM, Hancock AD, Reade MC, Silvester W. The impact of advance care planning on end-of-life care in elderly patients: randomized controlled trial. BMJ. 2010;340:c1345.

14. Wendler D, Rid A. Systematic review: the effect on surrogates of making treatment decisions for others. Ann Intern Med. 2011;154(5):336-346. 